Review

\title{
CUTANEOUS ANGIITIS (VASCULITIS)
}

JEFFREY P. CALLEN, M.D., JOSEPH J. CHANDA, M.D. AND JOHN J. VOORHEES, M.D.

The subject of vasculitis is a broad and detailed one, including many varied etiologies, clinical syndromes, classification systems, and pathological descriptions. The varying syndromes which have often been separated clinically are most likely manifestations of the same pathogenetic process immune-complex disease. In this paper, we will review 6 aspects of vasculitis: (1) historical perspectives and classifications, (2) clinical features, (3) etiological or predisposing factors, (4) pathogenesis, (5) relation of anatomical and nonimmunological factors to clinical presentation, and (6) evaluation and treatment. We will attempt to unify the various entities based on their similarities.

\section{Historical Perspectives and Classification}

The earliest classification of vasculitis was that of Zeek in $1952,{ }^{1}$ who reviewed the literature from 1886 to 1952 . During this period the literature concentrated on pathological descriptions and speculations as to etiologies, with lues, bacterial and viral infections, and various toxins being considered as possible causes. The terms vasculitis, periarteritis nodosa, and arteritis were used synonymously during this period, with periarteritis being the most commonly used term.

By the early 1950's the term periarteritis nodosa was indeed a broad one, encompassing necrotizing or hypersensitivity angiitis, polyarteritis, temporal arteritis, Wegener's granulomatosis, the allergic vasculitis of

Address for reprints: J. P. Callen, M.D., 554 Medical Towers South, Louisville, KY 40202.
From the Department of Dermatology, University of Michigan Medical School, Ann Arbor, Michigan

Churg and Strauss, and others. Zeek attempted to delineate 5 specific clinicopathological entities: hypersensitivity angiitis, allergic granulomatous vasculitis, rheumatic arteritis, periarteritis nodosa and temporal arteritis. She proposed that these entities be used in place of the then more general term periarteritis nodosa. However, the literature subsequent to her review has continued to propose multiple and varied classifications.

A significant problem in approaching the topic of vasculitis remains the student's coping with the numerous classifications. The difficulty was first summarized in 1802 by Heberden (requoted by Copeman), ${ }^{2}$ who stated: "There is a great variety of cutaneous disorders. Several of the appearances here mentioned have been distinguished among the ancient physicians by peculiar names: there is a great difficulty, though happily not much use, in ascertaining the appearances to which these names were appropriated; for this reason the ancient divisions and titles are very little regarded by the moderns. Many morbid appearances of the skin are judged to be proofs of a diseased constitution rather than merely local disorders of the part which is afflicted with them." This 150-year-old statement is still valid today. Briefly there are "many rashes; unnecessary names; and systemic significance." 2

Classifications have been based on the histological patterns of involvement, the type of 
Table 1. Cutaneous Signs of Vasculitis

Urticaria
Purpura (palpable)
Vesiculation-bulla
Nodule formation
Necrosis
Livedo reticularis

vessel involved, and the extent of clinical involvement-cutaneous, systemic or both. ${ }^{3}$ We believe that ideally a classification of vasculitis should separate disease entities according to differing pathogenic mechanisms, should provide some information about clinical features and presentation, and should separate diseases with varying prognoses. Unfortunately, no present system includes all of these features. Therefore, we think that the best classification of vasculitis limit the definition to those conditions which are characterized pathologically by infiltration with polymorphonuclear leukocytes, with fragmentation of nuclei, involving either small or large vessels. The terms vasculitis and angiitis should be used interchangeably. This definition will include the entities of hypersensitivity or necrotizing angiitis, anaphylactoid purpura (Schönlein-Henoch purpura), rheumatoid vasculitis, and periarteritis nodosa. The significant feature of all these entities is that they are characterized histologically by fibrinoid necrosis of vessel wall and leukocytoclasis (or fragmentation of neutrophils with nuclear dust). ${ }^{4}$ The problem of classification is thereby eliminated, thus enabling us to approach a group of diseases bearing many names but which have similar clinical presentation and pathogenic mechanisms.

\section{Clinical Features}

The clinical manifestations of vasculitis may be separated into cutaneous (Table 1) and systemic (Table 2) groups.

In 1964 Winkelmann and Ditto ${ }^{4}$ analyzed 38 cases of angiitis defined by leukocytoclasis and fibrinoid necrosis pathologically. The cutaneous lesions weie urticaria, petechiae, papules, plaques, nodules, bullae and necrotic ulceration. No single type of lesion predominated. Usually there was more than one type of lesion present. A universal finding was that of hemorrhage into the skin. Livedo reticularis was occasionally present. There was preferential involvement of dependent portions of the body, but lesions did occur elsewhere, including the oral mucosa. AIthough cutaneous vasculitis usually is seen with varied lesions, one type may predominate. Soter, Austen, and Gigli ${ }^{5}$ reported a series of 8 patients in whom chronic urticaria was the only sign of leukocytoclastic angiitis. The urticaria in these patients was atypical in that it was of long duration-up to 72 hours-and associated with an elevated Westergren erythrocyte sedimentation rate (ESR). Seven of 8 cases were accompanied by arthralgias. There was a low total hemolytic complement in 2 of the 8 patients. The authors conclude that urticaria associated with an elevated erythrocyte sedimentation rate may be suggestive of vasculitis. However, the duration of the urticaria may be a more valuable sign of vasculitis than an elevated erythrocyte sedimentation rate (JPC unpublished observation).

Systemic involvement in necrotizing angiitis is quite common. ${ }^{4,6-8}$ In Winkelmann's series only a small percentage of patients had disease limited to the skin. ${ }^{4}$ In 1965 McCombs 9 reported a series of 72 patients with confirmed pathological leukocytoclastic vasculitis. ${ }^{9}$ The data of both Winkelmann and McCombs are presented in Table 2.

Arthralgias occurred in approximately $1 / 3$ of the patients while arthritis was less common. Gl bleeding occurred in approximately $10-15 \%$ in each series. Renal involvement as manifested by hematuria was common, although azotemia was less frequent. Cardiorespiratory involvement was infrequent. The nervous system was more commonly involved in McComb's series. The presence of systemic involvement and the type of organ involved is similar to that seen in HenochSchönlein purpura characterized by purpuric 
Table 2. Systemic Involvement in Leukocytoclastic Angiitis (Number of Cases)

Series

\begin{tabular}{lrr} 
& \multicolumn{2}{c}{ Series } \\
Organ system & I (38 Cases) ${ }^{*}$ II (72 Cases) + \\
\hline Joints & 8 & 31 \\
$\quad$ Arthralgia & 14 & 12 \\
$\quad$ Arthritis & 6 & 9 \\
Gastrointestinal bleeding & & \\
Renal & 17 & 24 \\
$\quad$ Hematuria & 7 & 17 \\
$\quad$ Azotemia & & \\
Respiratory system & 4 & 7 \\
$\quad$ Upper & 12 & 22 \\
$\quad$ Lower & 2 & 5 \\
Heart & 8 & 27 \\
Nervous system & & \\
\hline
\end{tabular}

* Winkelmann, R. K. and Ditto, W. B., $1964^{4}$

t McCombs, R. P., $1965^{9}$

vasculitis with hematuria and Gl bleeding. ${ }^{10,11}$ It is also similar to polyarteritis which commonly is seen with neuropathy, renal disease, hypertension, abdominal pain, arthralgia, fever and weight loss. ${ }^{12-14}$ Although this disease less frequently produces cutaneous manifestations, the lesions are similar and forms limited to the skin exist.15,16,17 Rheumatoid vasculitis also has similar cutaneous manifestations and may have serious systemic involvement.8,17,18

Vasculitis has generally been reported to have a grave prognosis, particularly polyarteritis, and rheumatoid vasculitis. However, all of the aforementioned clinical syndromes have varied prognoses, depending mainly on the extent and type of systemic involvement. ${ }^{4,10,12-17,19}$ Cases of idiopathic cutaneous vasculitis without significant systemic involvement and with spontaneous resolution are frequent.

\section{Predisposing Factors}

The etiological or predisposing factors involved in vasculitis are listed in Table 3, which represents the work of Winkelmann ${ }^{4}$ (series 1), and $\mathrm{McCombs}^{9}$ (series 2). The pres-
Table 3, Etiology of "Vasculitis" *

\begin{tabular}{lrr}
\hline & \multicolumn{2}{c}{ Series } \\
& $1(38)^{*}$ & II (72)t \\
\hline Infection & $3-6$ & 22 \\
Drugs & 20 & 26 \\
Collagen-vascular & 3 & 12 \\
Lymphoproliferative & 0 & 5 \\
Unknown & 12 & 33 \\
\hline
\end{tabular}

* Winkelmann, R. K. and Ditto, W. B., $1964^{4}$

† McCombs, R. P., $1965^{\circ}$

ence of infection, particularly of the upper respiratory tract, before development of vasculitis, was common, as was drug ingestion. However, an overlap occurred since many patients with suspected infections had had medication. Vasculitis in association with rheumatoid arthritis and lupus erythematosus was also seen. Also, McCombs had 5 patients with tumors. Henoch-Schönlein purpura is commonly associated with antecedent infection or drug ingestion. ${ }^{11,20}$ Polyarteritis nodosa has been found to be commonly related to immune complexes formed by hepatitis-associated antigen and antibody, ${ }^{21}$ and it has been associated with other collagen-vascular diseases and with am. phetamine abuse. ${ }^{11}$

\section{Pathogenesis}

The association of vasculitis with autoim mune diseases prompted investigation int the immune system as a possible etiologica factor. Also, the association of vasculitis witl previous or coexistent infection prompter studies of bacterial antigens in the lesions Most investigators have viewed angiitis as Type 1 II reaction (or immune complex disol der). ${ }^{20,22-27}$ Parish $^{28-31}$ in 1971 presented series of controlled studies of patients wit vasculitis, in whom the serum and skin wer examined for immunoglobulins, bacteri: antigens, complement $\left(\beta_{1} \mathrm{C}\right)$ and $\mathrm{C}$-reactis protein. Immunoglobulins were in cutaneo vessel walls in only $50 \%$ of the patients ar $10 \%$ of controls. Only skin of patients wi 
vasculitis demonstrated complement in the lesions. C-reactive protein, streptococcal, candidal, and mycobacterial antigens were rarely found in association with vasculitis. Immunofluorescent staining of vasculitic lesions for soluble bacterial antigens was insignificant. A higher incidence of rheumatoid factor, anti-lgG, and immunoconglutinin was found in the sera of patients with cutaneous angiitis.

Parish concluded that there was indirect evidence that cutaneous vasculitis was caused by immune complexes, but that there was no evidence of bacterial antigens being important etiologically. In further experiments he examined sera of patients with and without vasculitis for antibodies to protein and polysaccharide of streptococci and staphylococci and found that the antibodyantigen complexes were no different in their ability to fix complement or release enzymes from white blood cells in vitro in patients with or without vasculitis. Therefore, he concluded that the properties of serum antibodies in convalescent antisera cannot determine susceptibility to vasculitis. He also concluded that bacterial antigens may play a direct role in potentiating immune-complex induced vascular damage via a Shwartzman reaction (direct effect of bacterial toxins which may cause fibrin deposition). These studies suggest that bacterial-antigen-antibody complexes are not of etiological significance, but that bacterial antigens may potentiate damage of other antigens-antibody complexes. This may explain the vasculitis which clinically seems to follow infection.

The similar nature of the inflammatory reaction in vasculitis to the experimental Arthus reaction (immune-complex disorder) in animals prompted investigations of the pathogenetic role of immune complexes. Much of the initial work done in the late $60^{\prime} \mathrm{s}$ has been well summarized by Copeman. ${ }^{2}$

In some series serum immunoglobulins are often nonspecifically elevated, but the levels of immunoglobulin may reflect underlying disease. ${ }^{11}$ The amount of immunoglobulin may be quite small in the serum with the majority being in tissue; this makes the total serum immunoglobulin level of little value in investigations of angitis. Early studies at the Mayo Clinic ${ }^{27,32}$ and in England ${ }^{33}$ demonstrated immunoglobulins and complement in the cutaneous lesions of patients with vasculitis. This is nonspecific etiologic evidence, as immunoglobulins may deposit secondarily in damaged tissue. ${ }^{34}$ However, the clinical distribution of the vasculitic lesions and their production by vasoactive amines suggests a role for circulating immune complexes. ${ }^{26}$ The leukocytoclasis suggests that the Shwartzman reaction may be pathogenetically important. ${ }^{30}$

McDuffie ${ }^{35}$ presented a series of 7 patients with cutaneous angiitis. The serum complement was depressed in all cases. In patients in whom the vasculitis disappeared, the complement levels returned to or toward normal. These findings are suggestive of the importance of immune complexes in vasculitis. However, subsequent studies failed to reveal immunoglobulins in a significant proportion of cases of acute cutaneous angiitis. ${ }^{28-31}$ This led to confusion, although the process was still believed by many to represent an Arthus reaction.

In 1971 Cream and associates ${ }^{36}$ studied the experimental Arthus reaction by immunofluorescence. They attempted to define the appearance and disappearance of immunoglobulin and complement in the lesions. After sensitization to ovalbumin, guinea pigs were given an intradermal injection of ovalbumin and then killed at varying times. The skin test site was then examined for immunoglobulin and complement. Controls were from normal skin in test animals and from unsensitized animals' skin test sites. The controls showed no immunofluorescence.

Clinically, the skin test sites showed erythema and induration within 10 minutes and hemorrhage within 1-2 hours. The lesion was most intense at 4 hours and was resolving at 18 hours. Histologically at 20 minutes there was vasodilation and margination of polymorphonuclear cells; at 1 hour there was cell migration through the vessel walls; at 4 
hours there was necrosis of many vessels. By 8 hours the perivascular nature of the infiltrate was less evident and mononuclear cells were seen, and by 18 hours only a patchy mononuclear infiltrate remained. Immunofluorescence appeared at 20 minutes and was most intense at 4 hours with granular deposits. At 8 hours only complement remained and by 18 hours no immunofluorescence was found.

Although this is an experimental animal study, the applicability to humans is potentially significant. It can be easily recognized that if an older lesion is studied by biopsy, immunofluorescence may not be demonstrated (possibly due to destruction by enzymes). Thus in both clinical studies and practice the failure to find immunoglobulin is not significant unless the lesion examined by biopsy is known to be an early lesion.

Cream $^{37}$ evaluated 32 patients with various cutaneous vasculitides for anticomplementary sera. The patient's serum was mixed with complement and then sensitized red blood cells were added. Anticomplementary activity was considered to be present if the red blood cells were not hemolyzed. The sera were heated to $56^{\circ} \mathrm{C}$ and then retested. Eleven patients had anticomplementary activity and in all cases the activity was inhibited or reduced by heating. Five of the patients with positive results had cryoglobulinemia. However, not all those with cryoglobulins had anticomplementary sera. There are 2 possible explanations for these results: (1) the presence of immune complexes capable of fixing complement or (2) the presence of inhibitors such as $\mathrm{C} 1$ esterase inhibitor or $\mathrm{C} 6$ inhibitors, each of these mechanisms being heat labile. This study shows that patients with angiitis may have circulating immune complexes which can fix complement in vitro. In vivo, their precipitation might initiate the complement cascade. Although indirect, this evidence strongly favors an Arthus type reaction for the pathogenesis of cutaneous angiitis.

Subsequent studies on the sera of patients with vasculitis have demonstrated $\mathrm{C} 1 \mathrm{q}$ preciptins, which measure the presence of serum immune complexes. ${ }^{38,39}$ Additional evidence of immune complex involvement in cutaneous angiitis has been reported by Sams. ${ }^{40}$ Skin biopsies of uninvolved and involved skin in 13 patients with necrotizing vasculitis were examined for the presence of immunoglobulins and complement components. Ten patients had positive staining in involved skin, and 7 patients had staining of the uninvolved skin with complement components of the classical pathway. The authors thought that this represented evidence of circulating immune complexes which were depositing in clinically normal skin. Their biopsies, however, were generally in close proximity to diseased areas.

Braverman and $\mathrm{Yen}^{23}$ were able to demonstrate immune complexes in vasculitic lesions induced by histamine in uninvolved normal skin of patients with leukocytoclastic angiitis. The histamine-induced lesions contained typical histological changes of vasculitis. Also on electron microscopy, immune complexes were present in nonmanipulated normal skin of patients with vasculitis but histologic changes were absent. The investigators believed that these findings indicate that immune complexes are deposited in vessels before tissue damage ensues and suggested that since immunofluorescence is frequently absent in older lesions histamine injection may aid in the demonstration of immunofluorescence in vasculitis.

Finally, Jones et al. ${ }^{41}$ reported a case of vasculitis in which injection of a patient's serum intradermally produced clinical lesions of vasculitis. Fractionation of the serum showed that this property was associated with $\mathrm{lgG}$, and the authors concluded that there was an immune complex present in this patient's serum. This is a clinical example of an Arthus reaction.

These studies have dealt mainly with patients with cutaneous vasculitis. Polyarteritis, a primary systemic vasculitis, may have a similar pathogenesis ${ }^{12,14,21,22,42,43}$ since studies have shown a high correlation with Australia antigen. Recently Trepo and his group $^{44}$ have studied the role of circulating complexes of hepatitis B antigen/antibody in 
the pathogenesis of vasculitic lesions of polyarteritis. The patients in this study were divided according to disease activity, and sera were obtained for hepatitis-associated antigen and hepatitis-associated antibody measurements. Sixty-five per cent of the samples contained hepatitis-associated antigen. Eight cases were found with antibody only.

The titers of antigen did not correlate with disease activity but clinical improvement correlated with disappearance of hepatitisassociated antigen and appearance of a low level of HB antibody. Seven patients with antibody only were in the quiescent group (4) or were in remission (3). Hepatitis-associated antigen (HBAg)-Hepatitis-associated antibody (HBAb) immune complexes are not able to induce liver damage in $\mathrm{HBAg}$ hepatitis, thus, the mechanisms of liver toxicity may be a cell-mediated phenomenon. However, polyarteritis associated with HBAg-HBAb immune complexes appears to be an Arthus (Type III) hypersensitivity reaction. The presence of immune complexes and their relationship to polyarteritis is curious because immune complexes should not passively deposit in larger vessels with fast flow, but rather should be deposited in smaller cutaneous vessels. ${ }^{20}$

Further studies by Sergent et al. ${ }^{14}$ have suggested that the vasculitis occurring with HBAg is not always a true polyarteritis. They found that only the presence of subclinical liver disease could separate those patients with hepatitis and necrotizing angiitis from patients with angiitis only. Also they reconfirmed the notion that the hepatitis and vasculitis were not mechanistically the same. ${ }^{14,42}$ In an additional study, they investigated 27 patients with hepatitis B antigen and found a strikingly high level of cryoproteins which had biological properties associated with immune complexes. ${ }^{45}$ Several of their patients with cryoproteins had manifestations of serum sickness. The authors suggested that the investigation of cryoproteins in patients with hepatitis may be of clinical and pathogenic importance.
Duffy et al. ${ }^{12}$ divided patients with HBAg hepatitis into 2 groups: (1) those with transient polyarthralgias and rashes (generally more benign disease), and (2) those with vasculitis. However, no skin biopsies were done despite the presence of urticarial and purpuric lesions in their first group. Probably their groups merge as those in the studies by Sergent et al. ${ }^{14}$

Similar studies on rheumatoid vasculitis suggest that it is a disease of immune complexes, ${ }^{8,18}$ since immune complexes are detectable in the sera and synovial fluids of patients with rheumatoid arthritis (RA) ${ }^{18}$ It has also been reported that cutaneous vessel immune deposits occur frequently in seropositive patients with rheumatoid arthritis, and that there was a slightly higher frequency of immune deposits in those patients with clinical vasculitis. ${ }^{8}$

It is apparent from these studies that the majority of indirect and direct evidence suggests that necrotizing angiitis, HenochSchönlein purpura, polyarteritis nodosa, and rheumatoid vasculitis are immune complex disorders or forms of Type III hypersensitivity.

\section{Relationship of Anatomic and Nonimmunological Factors to Clinical Presentation}

Two patterns of disease are found clinically: (1) a small punctate pattern and (2) a larger or reticulate pattern as in livedo reticularis. ${ }^{2,20}$ Both patterns have propensity for involvement of the legs. ${ }^{20}$ The interrelation of anatomical and nonimmunological factors responsible for these manifestations has been outlined by Copeman.20 Some are well worked out as being mechanistically important, others are only of hypothetical importance. The clinical presentations depend on the blood vessel affected (arterioles or venules) and their size and proximity to the skin. The nonimmunological factors involved are: (1) outflow blockade by red blood cells, platelets, or fibrin; (2) viscosity of blood; and (3) pressure-internal or external. ${ }^{46}$ These 3 factors are interrelated. 
Table 4. Evaluation of Patient with Cutaneous Angitis

1. History and physical examination

2. Complete blood count and platelet count

3. Urinalysis

4. Cryoglobulins, macroglobulins

5. Hepatitis-associated antigen-antibody

6. Coagulation and Fibrinolysis

7. Histology

8. Complement studies

9. Rule out infection (endocarditis)

10. Immunofluorescence (optional)

Studies of altered fibrinolysis have been done by Cunliffe et al.,"77 who reported 3 patients with vasculitis with decreased fibrinolytic activity in their blood as measured by the reciprocal of the eliglobulin lysis time. Subsequent studies on additional patients have shown similar findings. ${ }^{4,49}$ Also decreased tissue fibrinolytic activity in cutaneous lesion of vasculitis has been demonstrated. ${ }^{42,50}$ Thus the fibrinolytic system may be an important factor in amplifying the damage initiated by the immune complexes.

Other mechanisms which may be involved have been studied at length in experimental animals as reported by Cochrane. ${ }^{34}$ These data have been summarized by $\mathrm{Sams}^{26}$ in a previous review and will not be reviewed in this paper. Basically, immune complexes attain a certain critical size causing their precipitation between cells. This activates the complement cascade which leads to release of vasoactive amines, chemotaxis, and possible fibrinolytic blockade. As the inflammatory reaction progresses, necrosis and hemorrhage occur, producing the clinical signs of vasculitis.

\section{Evaluation and Treatment}

This discussion of classification, etiology and pathogenesis of vasculitis can be of much practical value when applied to evaluation and treatment. Based on the discussion, physicians evaluating patients with cutaneous angiitis should attempt to establish whether the involvement is limited to the skin or is systemic in nature (Table 4). A thorough history and physical examination are basic to this. A
Table 5. Treatment of Vasculitis

1. Symptomatic relief: elevation, frequent turning

2. Correction of coagulation-fibrinolytic system abnormalities: phenformin, ethylestrenol

3. Blockade of immune complex deposition, complement activation and polymorphonuclear leukocyte activity: corticosteroids, cytotoxic drugs

urinalysis is also a valuable screening tool in determining the presence of renal involvement. The use of invasive studies should depend on the individual case. Additional laboratory evaluation should include the coagulation and fibrinolytic tests, cryoprecipitable proteins, macroglobulins, and complement activation. Other causes of similar rash, particularly bacterial endocarditis, must be ruled out.51 The histology of the cutaneous disease should be reviewed. Immunofluorescence ${ }^{52}$ can be done on an early lesion or an induced lesion. ${ }^{23}$

Treatment of "vasculitis" should be directed at both symptoms and etiology (Table 5). Locally increased intravascular pressure may be relieved by elevation. Frequent turning also will decrease pressure on truncal lesions. Because altered fibrinolysis and coagulation may perpetuate the disease long after the initiating event, anticoagulants have been used with varying success. Also, antiplatelet drugs such as phenformin and ethylestrenol have been used. ${ }^{4-49}$ These agents also increase blood fibrinolytic activity; 53 they have been demonstrated to be useful and produce little toxicity. ${ }^{47,48}$ Other agents used with variable success rates have been sulfones and nicotinic acid. ${ }^{17}$

Because vasculitis appears to be an immune complex disorder, steroids have been suggested as being effective. ${ }^{19,26}$ Sams $^{26}$ suggests that because they appear to be effective in another immune complex disorder, systemic lupus erythematosus, they might have some benefit in the treatment of vasculitis. However, no controlled clinical study has demonstrated their usefulness in treatment of vasculitis and some reports have suggested that there is an unpredictable response. ${ }^{11}$ 
Lastly, cytotoxic agents have been used with variable response..$^{54}$

\section{Conclusion}

In conclusion, we believe that there are many similarities between the various entities characterized by leukocytoclastic angiitis, namely the clinical presentation, pathogenesis and relationship to internal disease. Those performing recent studies have been unable to demonstrate prognostic differences based on clinical criteria. Treatment regimens are nonspecific and symptomatic. Therefore, we conclude that these disorders should be grouped under one descriptive title, cutaneous angiitis, until pathogenetic, prognostic or therapeutic differences can be shown.

\section{Drug Names}

ethylestrenol: Maxibolin

phenformin: DBI

\section{References}

1. Zeek, P. M.: Periarteritis nodosa: A critical review. Am. J. Clin. Pathol. 22:777, 1952.

2. Copeman, P. W. M.: Livedo reticularis. Br. J. Dermatol. 93:519, 1975

3. Copeman, P. W. M., and Ryan, T. J.: The problems of classification of cutaneous angitis with reference to histopathology and pathogenesis. Br. J. Dermatol. 82 (Suppl.): 2, 1970.

4. Winkelmann, R. K., and Ditto, W. B.: Cutaneous and visceral syndrome of necrotizing or "allergic" angiitis: A study of 38 cases. Medicine 43:59, 1964.

5. Soter, N. A., Austen, K. F., and Gigli, I.: Urticaria and arthralgias as manifestations of necrotizing angiitis (vasculitis). J. Invest. Dermatol. 63:485, 1974.

6. Alarćon-Segovia, D., and Brown, A. L.: Classification and etiological aspects of necrotizing angiitides: An analytic approach to a confused subject with a critical review of the evidence for hypersensitivity in polyarteritis nodosa. Mayo Clin. Proc. 39:205, 1964.

7. Handel, D. W., Roenigk, H. H., Shainoff, J., and Deodhar, S.: Necrotizing vasculitis. Arch Dermatol. 111:847, 1975.

8. Luthra, H. S., McDuffie, F. C., Hunder, G. G., and Samayoa, E. A.: Immune complexes in sera and synovial fluids of patients with rheumatoid arthritis. J. Clin. Invest. 56:458, 1975.

9. McCombs, R. P.: Systemic "allergic" Vasculitis. JAMA 194:1059, 1965.

10. Duffy, J. D., Scherbel, A. L., Reidbord, H. E., and McCormack, L. S.: Necrotizing angiitis: I. A clinical review of twenty-seven autopsied cases. Cleveland Clin. Q. 32:87, 1965.
11. Ryan, T. J., and Wilkinson, D. S.: Cutaneous vasculitis (angiitis). In Textbook of Dermatology. Second edition. Edited by Rook, A., Wilkinson, D. S., and Ebling F. J. G., London, Blackwell, 1972, p. 920.

12. Duffy, J., Lidsky, M. D., Sharp, J. T., Davis, J. S., Person, D. A., Hollinger, F. B., and Min, K. W.: Polyarthritis, polyarteritis and hepatitis B. Medicine 55:19, 1976.

13. Ryan, T. J.: Polyarteritis nodosa in Textbook of Dermatology. Second edition. Edited by Rook, A., Wilkinson, D. S., and Ebling, F. J. G., London, Blackwell, 1972, p. 979.

14. Sergent, J. S., Lockshin, M. D., Christian, C. L., and Gocke, D. J.: Vasculitis with hepatitis B antigenemia: Long-term observations in nine patients. Medicine $55: 1,1976$.

15. Borrie, P.: Cutaneous polyarteritis nodosa. Br. J. Dermatol. 87:87, 1972.

16. Diaz-Perez, J. L., and Winkelmann, R. K.: Cutaneous periarteritis nodosa. Arch. Dermatol. 110:407, 1974.

17. Gilliam, J. N., and Smiley, J. D.: Cutaneous necrotizing vasculitis and related disorders. Ann. Allergy $37: 328,1976$.

18. Conn, D. L., Schroeter, A. L., and McDuffie, F. C.: Cutaneous vessel immune deposits in rheumatoid arthritis. Arthritis-Rheum. 19:15, 1976.

19. Sairanen, E., and Wasat-jerna, C.: Periarteritis nodosa. Acta Med. Scand. 191:501, 1972.

20. Copeman, P. W. M.: Cutaneous angiitis, J. Roy, Coll. Phy. 9:103, 1975.

21. Trepo, C. G., Zuckerman, A. J., Bird, R. C., and Prince, A. M.: The role of circulating hepatitis $B$ antigen/antibody immune complexes in the pathogenesis of vascular and hepatic manifestations in polyarteritis nodosa. J. Clin. Pathol. 27:863, 1974.

22. Christian, C. L., and Sergent, J. S.: Vasculitis syndromes: Clinical and experimental models. Am. J. Med. 61:385, 1976.

23. Baverman, I. M., and Yen, A.: Demonstration of immune complexes in spontaneous and histamineinduced lesions in normal skin of patients with leukocytoclastic angiitis. 1. Invest. Dermatol. $64: 105,1975$.

24. Copeman, P. W. M.: Investigations into the pathogenesis of acute cutaneous angitis. $\mathrm{Br}$. J. Dermatol. 82 (Suppl.): 51, 1970.

25. Friend, P., Repine, J. D. Kim, Y., Clawson, C. L., and Michael, A. F.: Deficiency of the second component of complement (C2) with chronic vasculitis. Ann. Int. Med., 8:813, 1975.

26. Sams, W. M., Thorne, E. G., Small, P., Mass, M. F., Mclntosh, R. M. and Stanford, R. E.: Leukocytoclastic vasculitis. Arch Dermatol. 112:219, 1976.

27. Schroeter, A. L., Copeman, P. W. M., Jordon, R. E., Sams, W. M., and Winkelmann, R. K.: Immunofluorescence of cutaneous vasculitis associated with systemic disease. Arch. Dermatol. 104:254, 1971.

28. Parish, W. E.: Studies on vasculitis. I. Immunoglobulins BIC, C-reactive protein and bacterial antigens in cutaneous vasculitis lesions. Clin. Allergy 1:97, 1971.

29. Parish, W. E.: Studies on vasculitis. II. Some properties of complexes formed of antibacteria! antibodies 
from persons with or without cutaneous vasculitis. Clin. Allergy 1:111, 1971.

30. Parish, W. E.: Studies on vasculitis. III. Decreased formation of antibody to M protein, Group A polysaccharide and to some endotoxins, in persons with cutaneous vasculitis after streptococcal infection. Clin. Allergy 1:295, 1971.

31. Parish, W. E.: Studies on vasculitis. IV. The low incidence of antibacterial anaphylactic antibodies in the sera of persons with cutaneous vasculitis following bacterial infection. Clin. Allergy 1:433, 1971.

32. Stringa, S. G., Bianchi, C., and Zingale, S. B.: Nodular vasculitis: Immunofluorescent study. J. Invest. Dermatol. 46:1, 1966.

33. Cream, J. J. : Immunofluorescent studies of the skin in cryoglobulinemic vasculitis. Br. J. Dermatol. 84:48, 1971.

34. Cochrane, C. G.: Mechanisms involved in the deposition of immune complexes in tissues. J. Exp. Med $134: 75,1971$

35. McDuffie, F. C.: Serum complement levels in cutaneous diseases. Br. ). Dermatol. 82 (Suppl.) 20, 1970.

36. Cream, J. J., Bryceson, A. D. M., and Ryder, G.: Disappearance of immunoglobulin and complement from the arthus reaction and its relevance to studies of vasculitis in man. Br. I. Dermatol. 84:106, 1971.

37. Cream, J. J.: Anticomplementary sera in cutaneous vasculitis. Br. J. Dermatol. 89:555, 1973.

38. Asghar, S. S., Faber, W. R., and Cormane, R. H.: Clq preciptin in the sera of patients with allergic vasculitis (Gougerot-Ruiter syndrome). J. Invest. Dermatol. $64: 113,1975$.

39. Soter, N. A., Austen, K. F., and Gigli, I.: The complement system in necrotizing angiitis of the skin. Analysis of complement component activities in serum of patients with concomitant collagenvascular diseases. J. Invest. Dermatol. 63:219, 1974.

40. Sams, W. M., Claman, H. N., Kohler, P. K., McIntosh, R. M., Small, P., and Mass, M. F.: Human necrotizing vasculitis immunoglobulins and complement in vessel walls of cutaneous lesions and normal skin. J. Invest. Dermatol. 64:411, 1975.

41. Jones, J. V., Cumming, R. H., Asplin, C. M., Harman, R. R., and Tribe, C. R.: A circulating immune complex producing inflammatory skin lesions. $\mathrm{Br}$.). Dermatol. 94:123, 1976.

42. Gocke, D. J.: Extra hepatic manifestations of viral hepatitis. Am. J. Med. Sci. 270:49, 1975.

43. Gocke, D. J., Hsu, K., Councilman, C., Bombardieri, S., Lockshin, M., and Christian, C. L.: Vasculitis in association with Australia antigen. J. Exp. Med 134:330, 1971.

44. Sun, N. C. J., Conn, D. L., Schroeter, A. L., and Kazmier, F. J.: Skin fibrinolytic activity in cutaneous and systemic vasculitis. Mayo Clin. Proc. 51:216, 1976.

45. Mclntosh, R. M., Koss, M. N., and Gocke, D. J.: The nature and incidence of cryoproteins in hepatitis $B$ antigen $\left(\mathrm{Hb}_{\mathrm{g}} \mathrm{Ag}\right)$ positive patients. Q. J. Med. 45:23, 1976.

46. Copeman, P. W. M., and Ryan T. J.: Cutaneous angiitis. Br. J. Dermatol. 85:205, 1971.

47. Cunliffe, W. J.: An association between cutaneous vasculitis and decreased blood fibrinolytic activity. Lancet $1: 1226,1968$.

48. Cunliffe, W. J., and Menon, I. S.: The association between cutaneous vasculitis and decreased blood fibrinolytic activity. Br. J. Dermatol. 84:99, 1971.

49. Parish, W. E.: Cutaneousvasculitis: Antigen-antibody complexes and prolonged fibrinolysis. Proc. Roy. Soc. Med. 65:6, 1972.

50. Dodman, B., Cunliffe, W. J., and Roberts, W. E.: Observations on tissue fibrinolytic activity in patients with cutaneous vasculitis. Br. J. Dermatol. 88:231, 1973.

51. Lawrence, E. C., and Mills, J.: Bacterial endocarditis mimicking vasculitis with steroid-induced remission. West. J. Med. 124:333, 1976.

52. Tuffanelli, D. L.: Cutaneous immunopathology: Recent observations. J. Invest. Dermatol. 65:143, 1975

53. Isacson, S., and Nilsson, I. M.: Effect of treatment with combined phenformin and ethylestrenol on the coagulation and fibrinolytic systems. Scand. J. Haemat. 7:404, 1970.

54. Tuma, S., Chaimovitz, C., Szylman, P., Gellei, B., and Better, O. S.: Periarteritis nodosa in the kidney. JAMA $235: 280,1976$.

\section{Male Contraceptives}

Research in human reproduction has been stimulated in recent years by increasing awareness of the worldwide threat posed by unchecked population growth. Much of this research has been directed toward improving technics of contraception. The efficacy of available contraceptives for men has lagged well behind those in use by women. Much recent work has been aimed at correcting this deficiency through the development of safe, reliable and reversible technics for male contraception. Although optimal means are not yet available, limited clinical trials of several new methods have yielded encouraging results.-Brenner, W. I., deKretser, M.D., The Prospects For New, Reversible Male Contraceptives. N. Engl. I. Med. 295:1111, 1976. 